\title{
Drug-induced Anti-Histone Autoantibodies Display Two Patterns of Reactivity with Substructures of Chromatin
}

\author{
Rufus W. Burlingame and Robert L. Rubin \\ W. M. Keck Autoimmune Disease Center, Department of Molecular and Experimental Medicine, \\ Research Institute of Scripps Clinic, La Jolla, California 92037
}

\begin{abstract}
Increasing evidence suggests that autoantibodies in the rheumatic diseases are a consequence of immune selection by selfmaterial, but the nature of the in vivo immunogen is unknown. Insight into this problem may be obtained by measuring autoantibody binding to various forms of a target antigen. Antihistone antibodies arising as a side effect of therapy with various drugs offer an opportunity to explore this premise because many forms of histone have been characterized and adapted to ELISA formats. Two patterns of antibody reactivity were observed. All 21 patients with symptomatic procainamide-induced lupus and 7 of 12 patients with quinidine-induced lupus had IgG antibodies reacting predominantly with the (H2A-H2B)-DNA complex and with chromatin. In contrast, antibodies in 19 of 24 patients taking procainamide without accompanying lupus-like symptoms did not show any pattern. The second pattern was observed in 18/19 chlorpromazinetreated patients and 14/17 patients with hydralazine-induced lupus in which IgM antibodies displayed more reactivity with DNA-free histones than with the corresponding histone-DNA complexes and almost no binding to H1-stripped chromatin. Absorption studies were entirely consistent with these results. Thus, the two patterns of reactivity with nucleosomal components reflect the molecular substructure of chromatin, suggesting that two processes underlie antihistone antibody induction by drugs. In one, IgG autoantibodies appear to be elicited by chromatin, whereas in the other, autoimmune tolerance to native chromatin appears largely intact, and IgM antibodies may be driven by DNA-free histone. (J. Clin. Invest. 1991. 88:680690.) Key words: procainamide $\bullet$ hydralazine $\bullet$ quinidine $\bullet$ chlorpromazine $\bullet$ drug-induced lupus
\end{abstract}

\section{Introduction}

Autoantibodies reactive with histones have been observed in the sera of a high percentage of patients treated with certain drugs, particularly procainamide (p-amino- $N$-[2-diethylaminoethyl]benzamide), hydralazine (1-hydrazinophthalazine), and chlorpromazine (2-chloro-10-[3-dimethylaminopropyl]phenothiazine) (for reviews see 1, 2). Approximately 15-20\%

Address reprint requests to Robert L. Rubin, BCR-6, Scripps Clinic and Research Foundation, 10666 North Torrey Pines Road, La Jolla, CA 92037.

Received for publication 30 October 1990 and in revised form 5 March 1991.

J. Clin. Invest.

(C) The American Society for Clinical Investigation, Inc.

$0021-9738 / 91 / 08 / 0680 / 11 \quad \$ 2.00$

Volume 88, August 1991, 680-690 of patients taking procainamide (3) and 5-10\% treated with hydralazine (4) develop symptoms of systemic lupus. In contrast, virtually no patients taking chlorpromazine develop such symptoms (5). Lupus-like symptoms are occasionally induced by quinidine (6'-methoxycinchonan-9-ol) (6), and individual case reports of lupus related to long-term ingestion of many other drugs have been reported $(1,2)$.

There are three major reasons for studying the specificity of autoantibodies. Associations between the presence of particular antibodies and disease syndromes have helped in diagnosing some autoimmune disorders and directing the subsequent treatment of patients. The fine specificity of the autoantibodies may yield insight into their etiology and the nature of the putative in vivo immunogen. Finally, well-defined autoantibodies have proven to be useful tools in characterizing the function of a number of important cellular proteins (for review see 7).

IgG antibodies reacting with the native $\mathrm{H} 2 \mathrm{~A}-\mathrm{H} 2 \mathrm{~B}$ dimer but much less with the individual histones $\mathrm{H} 2 \mathrm{~A}$ and $\mathrm{H} 2 \mathrm{~B}$ were reported in patients with procainamide-induced lupus (8-10). In patients treated with hydralazine, antibody reactivity with individual histones has been described using the Western blot technique. However, inconsistencies were observed among the various studies $(9,11,12)$ and little diagnostic utility or insight into the structure of the putative histone immunogen was derived. The pronounced antigenicity of the H2A-H2B dimer in procainamide-induced lupus suggested that systematic studies using a comprehensive panel of histone-histone and histoneDNA complexes in their native quaternary forms might provide more insight into the origin of antihistone antibodies than studies on the antigenicity of individual histones.

To explore this possibility, we developed novel substrates for ELISA based on current concepts of histone and chromatin structure (reviewed in 13). If chromatin is briefly digested with micrococcal nuclease, particles called nucleosomes are produced (14) consisting of the (H2A-H2B-H3-H4) ${ }_{2}$ histone octamer wrapped within $\sim 200$ basepairs of DNA, with histone $\mathrm{H} 1$ on the outside of this complex. Subnucleosome particles can be isolated consisting of $\mathrm{H} 1$ with $60-70$ basepairs of DNA, $\mathrm{H} 2 \mathrm{~A}-\mathrm{H} 2 \mathrm{~B}$ with $50-60$ basepairs of DNA, and (H3-H4) ${ }_{2}$ with 70-80 basepairs of DNA if chromatin is more extensively digested with micrococcal nuclease and treated with $3 \mathrm{M}$ urea (15), as illustrated in Fig. 1. Stable histone-histone complexes, free of DNA, can also be isolated. The (H2A-H2B-H3-H4) octamer can be separated from $\mathrm{H} 1$, and then dissociated into two $\mathrm{H} 2 \mathrm{~A}-\mathrm{H} 2 \mathrm{~B}$ dimers and an $(\mathrm{H} 3-\mathrm{H} 4)_{2}$ tetramer (16). The $\mathrm{x}$-ray crystallographic structure of the histone octamer, which has a tripartite organization with two $\mathrm{H} 2 \mathrm{~A}-\mathrm{H} 2 \mathrm{~B}$ dimers in association with the $(\mathrm{H} 3-\mathrm{H} 4)_{2}$ tetramer $(17,18)$, supports the interpretation that the above structures are physiologically relevant. Thus, the complicated histone-DNA structure in chromatin can be chemically dissected, and stable components with welldefined biophysical properties (19-22) can be isolated. 12 histone-histone and histone-DNA complexes comprising the sub- 


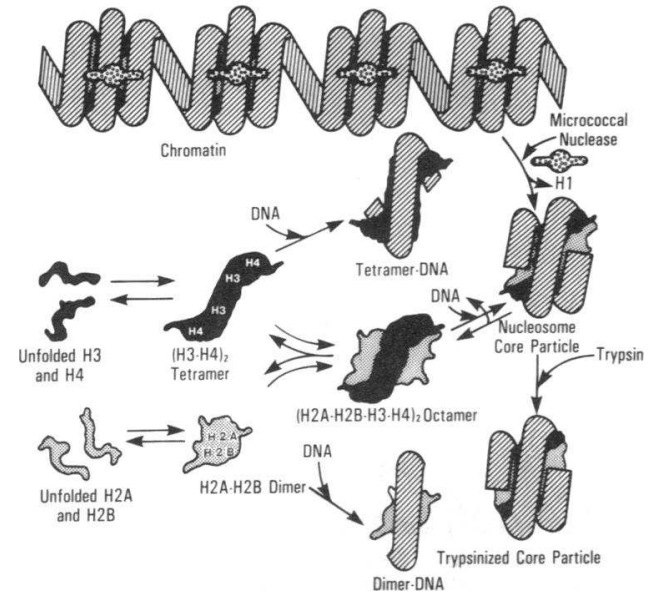

Figure 1. Interactions among the core histones and DNA. The various substructures of chromatin are depicted based on the biochemical properties displayed by subnucleosome particles (15) and by histones (16). The shapes of the particles are based on the $x$-ray crystallographic structure of the nucleosome core particle (17).

nucleosome organization of chromatin were applied to ELISA formats to characterize drug-induced antihistone antibodies in the context of chromatin structure.

\section{Methods}

Chromatin, histone, and subnucleosome preparations. Nuclei were isolated from calf thymus (Pel-Freeze Biologicals, Rogers, AR) and whole chromatin, soluble H1-stripped chromatin (14), and H1-stripped trypsinized chromatin (23) were made with slight modifications (24). Histones $\mathrm{H} 1, \mathrm{H} 2 \mathrm{~A}-\mathrm{H} 2 \mathrm{~B}$, and $(\mathrm{H} 3-\mathrm{H} 4)_{2}$ were prepared by methods described in detail elsewhere (24), and their structures have been shown to be native by a number of criteria (reviewed in 13). Histone-DNA complexes were reconstituted in a manner shown to resemble native chromatin (25) using high to low ionic strength dialysis (24). Calf thymus DNA (Calbiochem Corp., La Jolla, CA) was further purified by digestion with proteinase $\mathrm{K}$, extraction with phenol, and digestion with S1 nuclease $(26,27)$.

ELISA. Immulon II (Dynatech Laboratories, Inc., Alexandria, VA) microtiter plates were incubated with each histone-containing antigen preparation at $2.5 \mu \mathrm{g} / \mathrm{ml}$, and the ELISA was performed as described (26). Briefly, sera were diluted 1:400 in serum diluent $B$. The bound antibodies were detected with affinity-purified peroxidase conjugated goat anti-human IgG or IgM (Caltag Inc., South San Francisco, CA). After addition of the substrate, optical densities were determined after $\sim 10 \mathrm{~min}$ and after $60 \mathrm{~min}$ using a spectrophotometer (MR600; Dynatech). If the optical density at $60 \mathrm{~min}$ was greater than the limit of detection of the spectrophotometer ( 2 OD), the final optical density was calculated by extrapolation (24).

The anti-IgG peroxidase conjugate was tested for reactivity with human myeloma proteins representing all gamma chain isotypes, as previously described (28). At a plated myeloma protein concentration of $2.5 \mu \mathrm{g} / \mathrm{ml}$, the relative reactivity of the anti-IgG reagent with IgGl, $\operatorname{IgG} 2, \operatorname{IgG} 3$, and IgG4 was $1.00,0.94,1.01$, and 0.81 , respectively. This uniformity in IgG isotype reactivity ensures that any observed differences in IgG binding to a series of antigens are not due to differences in the IgG subclasses expressing specificity for a particular antigen.

The micro bicinchoninic acid protein assay (Pierce Chemical Co., Rockford, IL) was used to quantitate the protein bound to the wells of the microtiter plate as described (29). Three mouse monoclonal antibodies specific for DNA $(30,31)$, were used as the primary antibody in an ELISA to quantitate each solid phase antigen that contained DNA.
Absorption studies. Sera were diluted so that they would yield an OD of $<3$ on either dimer-DNA or tetramer. Half of each diluted serum was mixed with whole chromatin and the other half with a suspension of collagen (Worthington Biochemical Corp., Freehold, NJ) at a final concentration of $22 \mu \mathrm{g} / \mathrm{ml}$. This concentration of chromatin absorbed $>95 \%$ of the anti-stripped chromatin reactivity of a prototype serum. Incubation proceeded for $2 \mathrm{~h}$ at room temperature with gentle rotation. The absorbent was removed by centrifugation for 5 min in an Eppendorf microfuge, and the supernatant was used in ELISA in the normal manner. Antibodies to tetanus were measured by ELISA as previously described (28).

Sera selection. The normal sera came from laboratory and clerical personnel. The sera from symptomatic and asymptomatic patients treated with procainamide have been described (10), and another welldefined procainamide-induced lupus patient was added to that group. Sera from schizophrenic patients treated with chlorpromazine for $>3$ yr were obtained from Dr. M. H. Zarrabi of the V. A. Medical Center, Northport, NY, and none of these patients had symptoms of lupus as previously described (32). 13 of 17 patients with lupus induced by hydralazine and 9 of 12 with quinidine-induced lupus were evaluated at the Division of Clinical Rheumatology at Scripps Clinic. The other sera were obtained from outside physicians who provided extensive clinical information at the time of suspected drug-induced lupus and follow-up visits. All patients were considered to have drug-induced lupus based on symptoms of polyarthralgia, myalgia, constitutional symptoms, and occasionally arthritis, and whose symptoms resolved following discontinuation of the drug.

Data analysis. All ELISA data were entered into a Lotus 1-2-3 spread-sheet (Lotus Development Corp., Boston, MA). The average optical density plus 2 SD of 20 normal sera was calculated for each substrate. This value was subtracted from the optical density of each patient serum for the corresponding substrate to yield antibody activity above normal binding. This latter value was used for all data analysis and was graphed with routines contained in Lotus and the graphics program Freelance (Lotus Development Corp., Boston, MA). Statistical analyses were performed with the aid of routines in the program.

Sodium dodecyl sulfate discontinuous gel electrophoresis. Gel electrophoresis was performed as described (33), with the modification that the acrylamide was $15 \%$ and the bis-acrylamide was $0.4 \%$ in the separating gel and $6 \%$ and $0.8 \%$, respectively, in the stacking gel.

\section{Results}

Antigens for ELISA. All histone preparations and H1-stripped chromatin were essentially pure as judged by SDS gel electro-

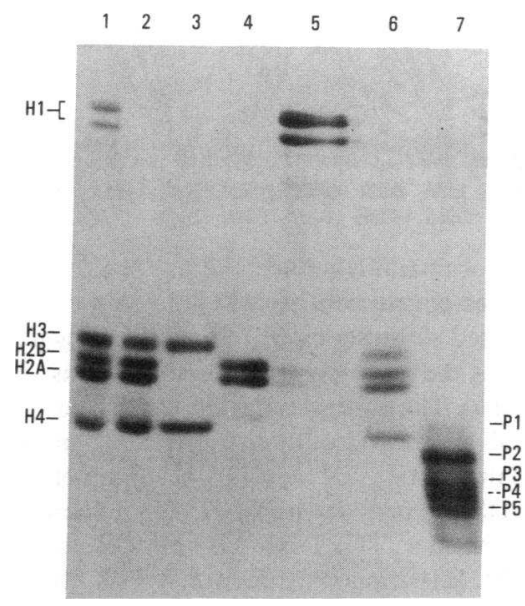

Figure 2. Histone composition of various chromatin preparations used in ELISA. The samples applied to an SDS PAGE gel were: lane 1 , total acid extracted histones; lane 2, the core histone octamer; lane 3, the (H3$\mathrm{H} 4)_{2}$ tetramer; lane 4 , the H2A-H2B dimer; lane $5, \mathrm{H} 1$; lane $6, \mathrm{H} 1$ stripped chromatin; and lane 7, trypsinized H1stripped chromatin. The light band in the dimer preparation that mi-

grates slightly slower than $\mathrm{H} 4$ is $\mathrm{c}-\mathrm{H} 2 \mathrm{~A}$, a form of $\mathrm{H} 2 \mathrm{~A}$ with its 15 carboxy-terminal amino acids removed (47). 
phoresis (Fig. 2). The $\mathrm{H} 1$ lane was intentionally overloaded to demonstrate that there was no detectable contamination by nonhistone proteins, but a 5-10\% contamination with the H2A-H2B dimer. The trypsinized chromatin yielded the array of histone polypeptides expected of the limit digest $(23,34)$. An agarose gel of the DNA from the chromatin fractions showed the expected 200-bp ladder, while the DNA used in reconstituting subnucleosome structures and the DNA assays consisted of a range of high molecular weight molecules (24).

Direct quantitation of protein and DNA bound to the ELISA plate wells demonstrated similar amounts of all the antigens. In addition, the orientations of the DNA-free histones and the histone-DNA complexes were shown to be random on the ELISA plate, substantiating the validity of comparing the antihistone antibody reactivities among these different substrates in the ELISA format (24).
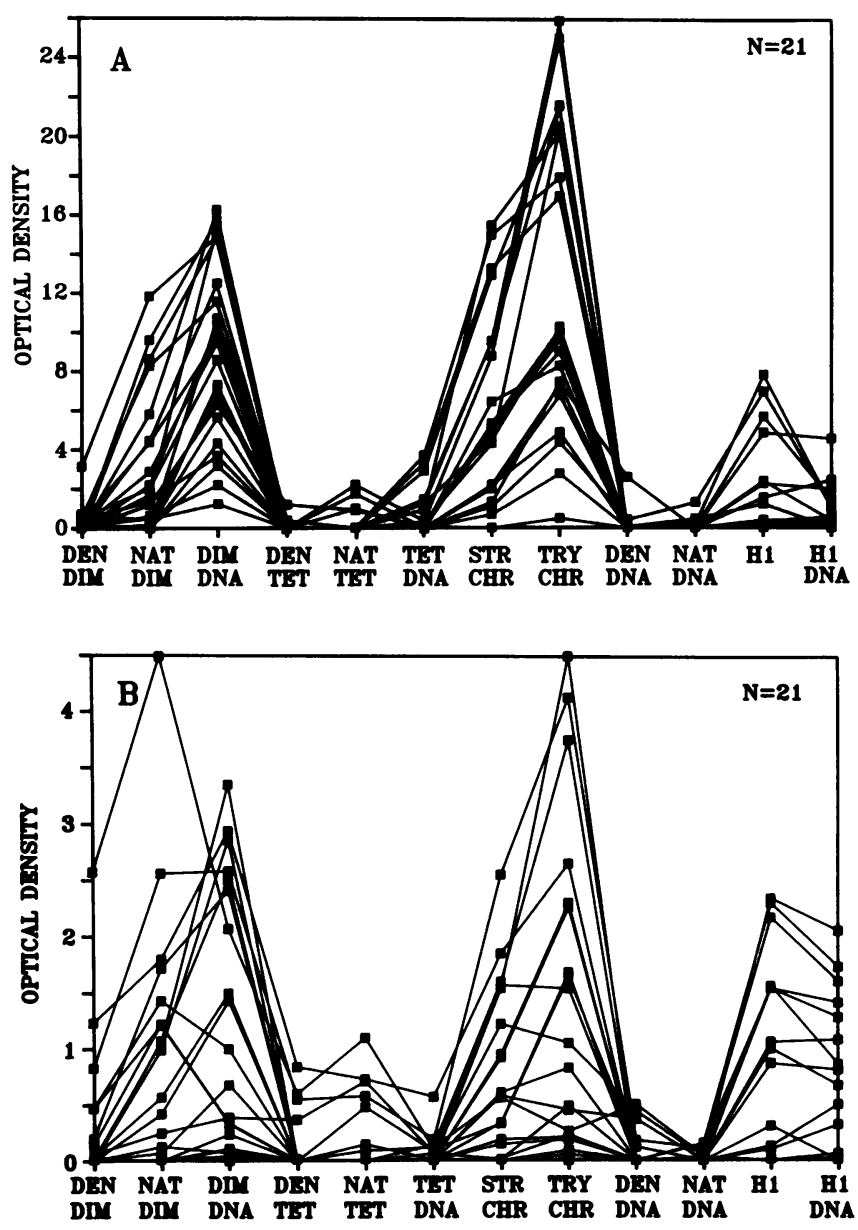

Figure 3. Autoantibodies in procainamide-induced lupus. The data points connected by lines are the optical densities of each patient's serum measured on the indicated substrate by ELISA and corrected for normal serum binding. Thus, the reactivity above 0 on the $y$ axis represents binding above normal. The abbreviations for the twelve substrates are: DEN DIM, SDS and heat denatured H2A-H2B dimer; NAT DIM, native H2A-H2B dimer; DIM DNA, (H2A-H2B) dimerDNA complex; DEN TET, SDS and heat denatured $\mathrm{H} 3-\mathrm{H} 4$ tetramer; NAT TET, native (H3-H4) $)_{2}$ tetramer; TET DNA, (H3-H4) $)_{2}$ tetramer-DNA complex; STR CHR, H1-stripped chromatin; TRY CHR, trypsinized H1-stripped chromatin; H1 DNA, H1-DNA complex. $(A)$ IgG antibodies; $(B)$ IgM antibodies. Note that $A$ and $B$ are drawn to different scales.
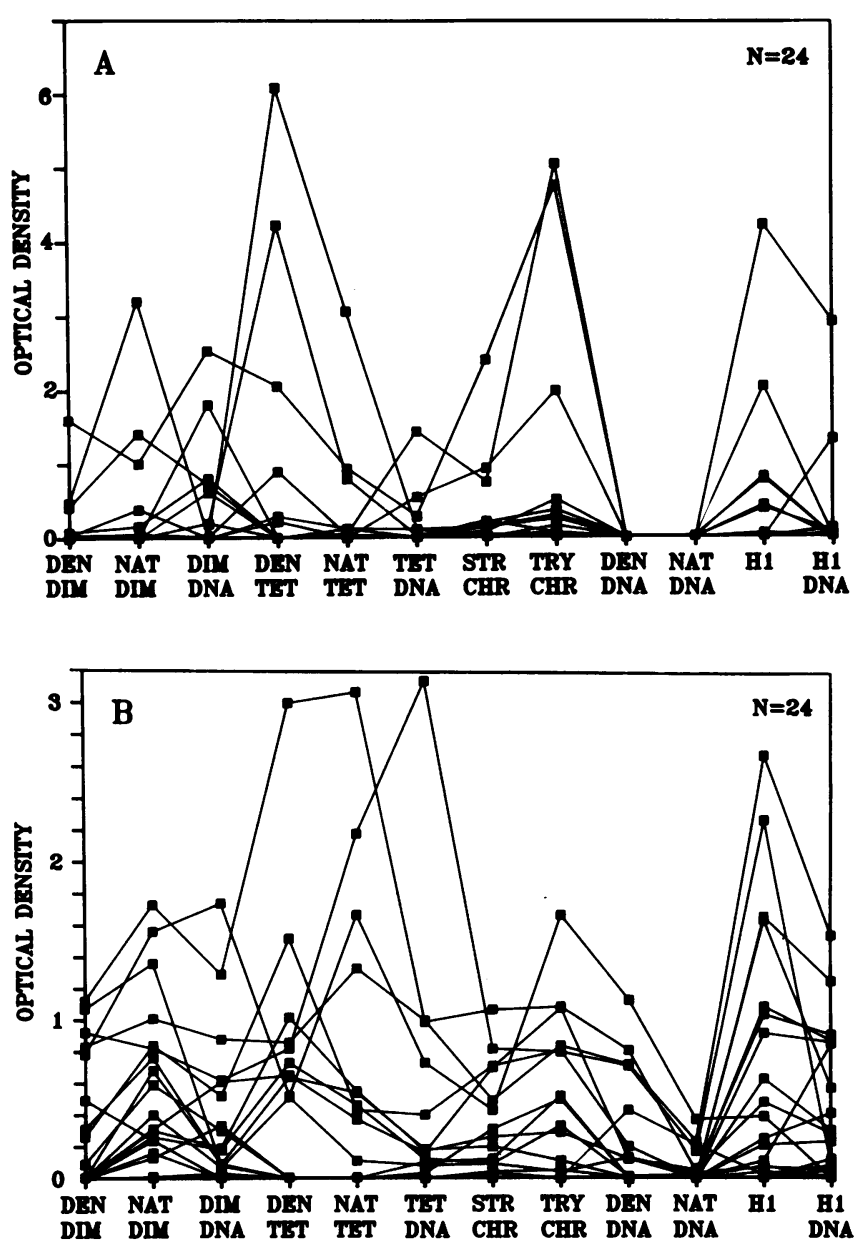

Figure 4. $(A)$ IgG and $(B)$ IgM autoantibodies in asymptomatic procainamide-treated patients. The details are the same as in Fig. 3.

ELISA of sera from patients with procainamide-induced lupus. The sera of all 21 patients with procainamide-induced lupus contained IgG antibodies that showed a strikingly similar pattern of reactivity on the set of histone, DNA, and histoneDNA substrates (Fig. $3 A$ ). Negligible antibody reactivity with the SDS and heat denatured $\mathrm{H} 2 \mathrm{~A}$ and $\mathrm{H} 2 \mathrm{~B}$ was observed, most sera showed a strong reaction with the native $\mathrm{H} 2 \mathrm{~A}-\mathrm{H} 2 \mathrm{~B}$ dimer, and all displayed an increased binding to the (H2A-H2B)-DNA complex. In contrast, all these sera displayed much less relative reactivity with denatured $(\mathrm{H} 3-\mathrm{H} 4)_{2}$ tetramer, the native $(\mathrm{H} 3-$ $\mathrm{H} 4)_{2}$ tetramer, and the ( $\left.\mathrm{H} 3-\mathrm{H} 4\right)_{2}$-DNA complex. Seven sera showed significant binding to the tetramer-DNA complex, but this was only an average of $22 \% \pm 17 \%$ (SD) of their optical density on the dimer-DNA complex. All sera but one reacted strongly with $\mathrm{H} 1$-stripped chromatin and all showed an increase in binding to trypsinized H1-stripped chromatin. Most of the sera did not react with denatured DNA, and none reacted with native DNA. Seven of 21 sera reacted with $H 1$, but in contrast to the results with the H2A-H2B dimer, all seven sera showed decreased binding with H1-DNA.

Because of the large number of samples and the uniformly low reactivity with certain substrates, it is not possible to trace the reactivity of each serum on all the antigens. The data are presented this way to demonstrate the qualitative similarity among the patients in this clinical group despite the wide varia- 


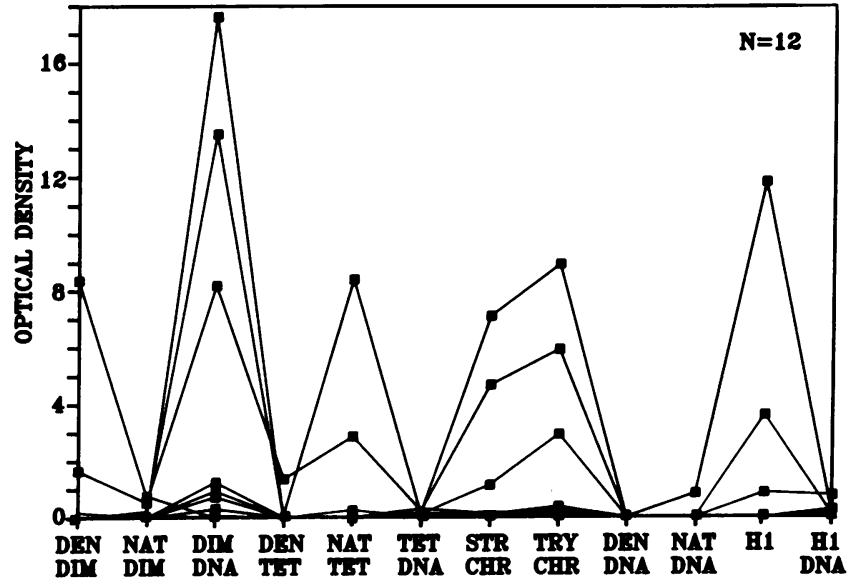

Figure 5. IgG autoantibodies in quinidine-induced lupus. The details are the same as in Fig. 3.

tion in antibody amounts. The continuous lines connecting the antigen-binding activities of the sera rarely overlap, indicating that all the sera displayed the same hierarchy of reactivities with the components of the antigen set.

Serial dilution of selected sera showed that if the maximum OD on any antigen was $<12$, the relative reactivity to the antigens at the 1:400 dilution was identical at higher dilutions. The eight sera with OD $>12$ on some antigens also retained the same pattern of reactivity at higher dilution, but a greater percentage of their IgG antibodies were directed against dimerDNA and chromatin.

The IgM antibodies displayed a related pattern of reactivity (Fig. $3 B$ ). Three sera had no IgM antibodies that reacted above normal with any of the histone or chromatin substrates. Of the sera that did react, seven showed an equal or higher binding with the DNA-free H2A-H2B dimer than with the (H2AH2B)-DNA complex or with chromatin. The other sera showed a pattern of reactivity very similar to that of the IgG antibodies. Thus, IgM antibodies in procainamide-induced lupus patients were more heterogeneous in binding specificity than IgG antibodies, but still retained predominant reactivity with structures containing the $\mathrm{H} 2 \mathrm{~A}-\mathrm{H} 2 \mathrm{~B}$ dimer.

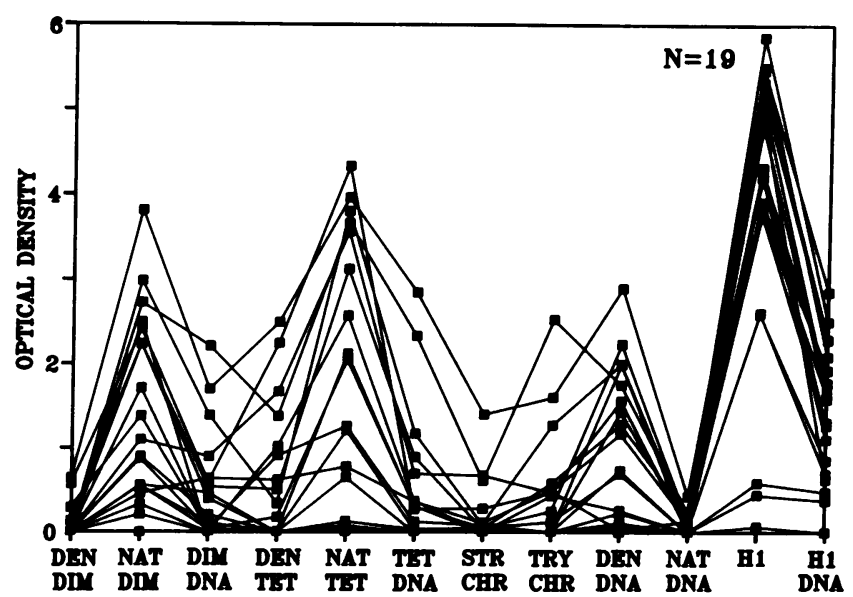

Figure 6. IgM autoantibodies in chlorpromazine-treated patients. The details are the same as in Fig. 3.
Asymptomatic patients treated with procainamide. The IgG antibodies in patients undergoing prolonged therapy with procainamide without having any symptoms of drug-induced lupus did not display the pattern of reactivity characteristic of the group with symptoms (Fig. $4 \mathrm{~A}$ ). The majority of patients did not have IgG antibodies that reacted with any of the substrates. Only six out of the 24 sera contained IgG antibodies reactive with the (H2A-H2B)-DNA complex. However, one of these six sera showed a decrease in reactivity with the (H2AH2B)-DNA complex compared to DNA-free H2A-H2B, and this serum did not react at all with chromatin, while the other five did. Their reactivity with (H2A-H2B)-DNA and chromatin was low compared to the symptomatic patients. This lower reactivity would be even more striking if Figs. $3 A$ and $4 A$ were drawn to the same scale. Three sera reacted with the DNA-free (H3-H4) 2 tetramer and showed enhanced binding to SDS and heat denatured $\mathrm{H} 3$ and $\mathrm{H} 4$. None of these sera contained IgG antibodies that reacted with native or denatured DNA.

The majority of the asymptomatic procainamide-treated patients had IgM antibodies that reacted with the DNA-free histones (Fig. $4 B$ ). In contrast to their counterparts from symptomatic patients, most of these antibodies also reacted with the denatured histones and displayed a decrease in antibody reactivity to the histone-DNA complex compared with the corresponding DNA-free histones. Relatively weak reactivity with
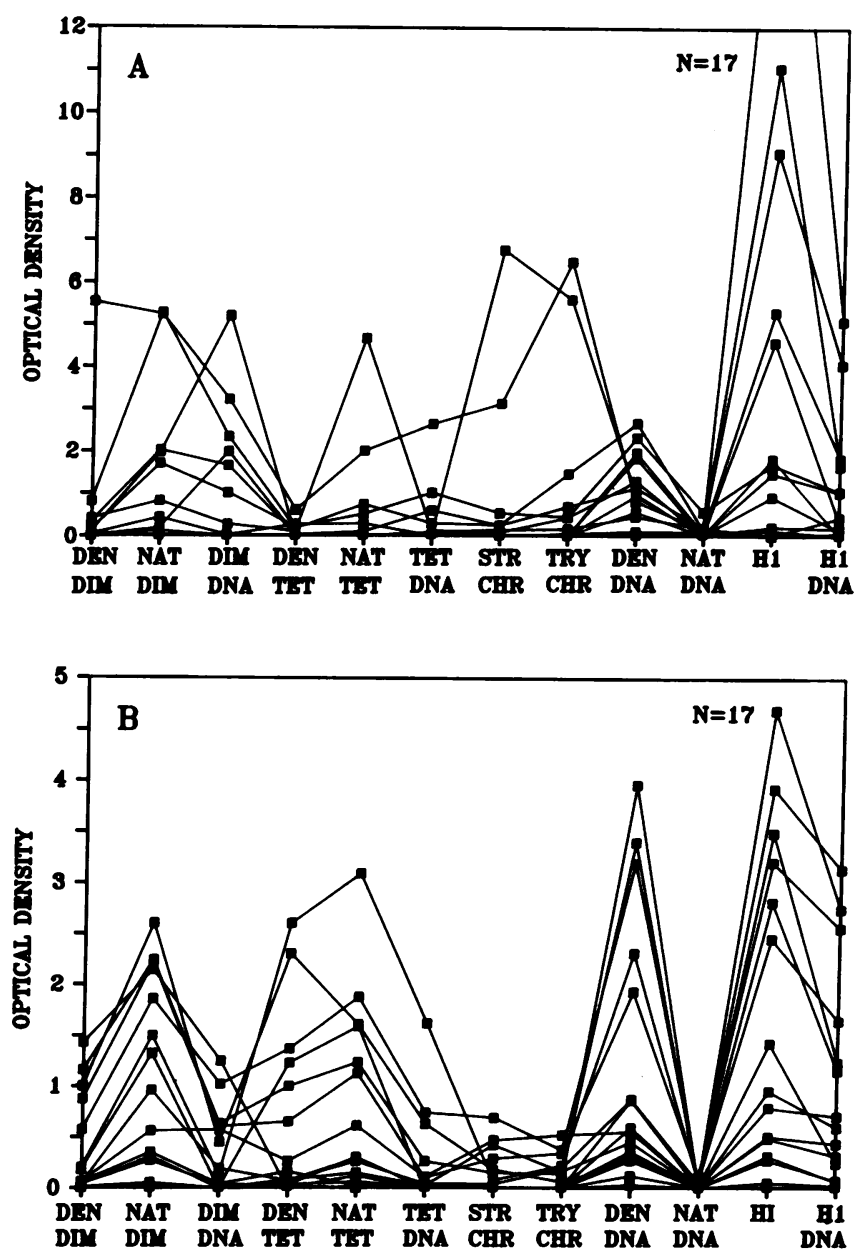

Figure 7. $(A) \operatorname{IgG}$ and $(B)$ IgM autoantibodies in hydralazine-induced lupus. The details are the same as in Fig. 3. 


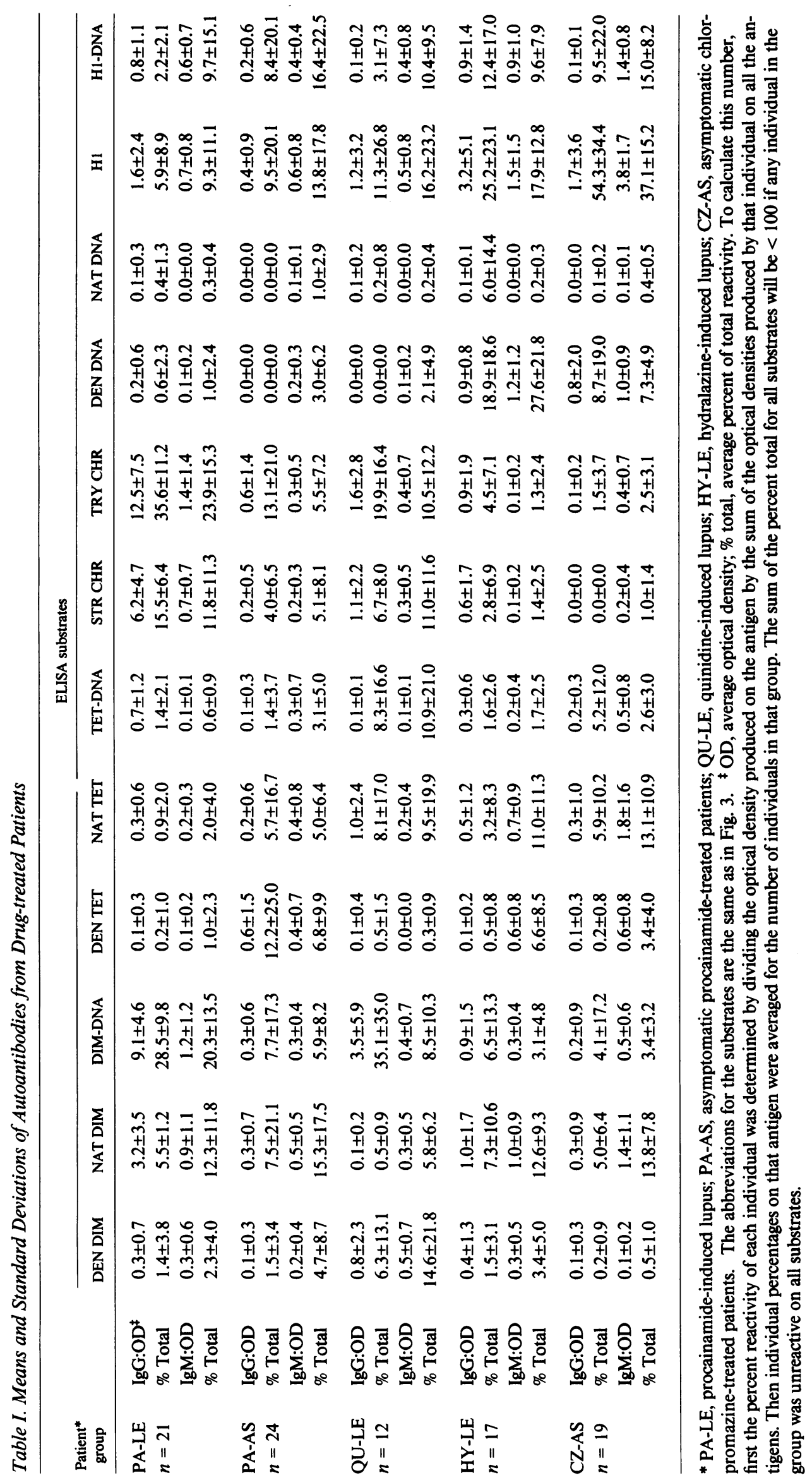


stripped or trypsinized chromatin was exhibited by half the sera, which also bound to denatured DNA.

Antibodies from quinidine-treated patients. As shown in Fig. 5 the IgG antibodies from some patients with quinidine-induced lupus showed a pattern of reactivity that was similar, but not identical, to the pattern displayed by patients with procainamide-induced lupus. Seven of the 12 sera reacted with the (H2A-H2B)-DNA complex, and the three highest also reacted with $\mathrm{H} 1$-stripped chromatin and trypsinized $\mathrm{H} 1$-stripped chromatin. Of the five sera that did not react with dimer-DNA, two showed no reactivity on the substrates tested, one reacted strongly on denatured dimer, native tetramer, and $\mathrm{H} 1$, and the other two reacted weakly with native tetramer or H1. None of the patients had IgG antibodies to denatured DNA. One unique feature of the pattern shown by the seven patients with IgG antibodies to the dimer-DNA complex is their lack of reaction with the DNA-free H2A-H2B dimer. This contrasts with symptomatic procainamide-treated patients in which 17 of 21 sera showed a positive reaction with the $\mathrm{H} 2 \mathrm{~A}-\mathrm{H} 2 \mathrm{~B}$ dimer.

10 of 12 sera from patients treated with quinidine had IgM antibodies that reacted with denatured and native $\mathrm{H} 2 \mathrm{~A}-\mathrm{H} 2 \mathrm{~B}$, while only one reacted with denatured or native tetramer. Half of the sera reacted with $\mathrm{H} 1$-stripped chromatin or trypsinized H1-stripped chromatin (Table I).

Antibodies from chlorpromazine-treated patients. Only six of the 19 patients taking chlorpromazine had IgG antibodies reactive with a substrate other than $\mathrm{H} 1$, and no consistent pattern was observed. Of particular note was the complete absence of reactivity with $\mathrm{H} 1$-stripped chromatin (Table I). In contrast, all the patients had IgM antihistone antibodies, and a consistent pattern of reactivity was observed (Fig. 6). 18 out of 19 patients reacted with the $\mathrm{H} 2 \mathrm{~A}-\mathrm{H} 2 \mathrm{~B}$ dimer and 16 reacted with the (H3-H4) ${ }_{2}$ tetramer. All sera showed a higher reactivity with the native complexes than with the denatured complexes, and in all but one case, the sera displayed a higher reactivity with the DNA-free histone complex than with the corresponding histone-DNA complex. All 19 sera reacted most strongly with $\mathrm{H} 1$ and less well with H1-DNA. In addition, 16 sera reacted with denatured but not native DNA. The lowest reactivity for all samples was with $\mathrm{H} 1$-stripped chromatin, demonstrating a pattern of pronounced specificity for the DNA-free histones.

Antibodies from hydralazine-treated patients. Half of the hydralazine-treated patients did not have IgG antibodies that reacted with the substrates tested (Fig. $7 \mathrm{~A}$ ). Of the sera that reacted, the binding pattern was nonuniform. $\mathrm{H} 1$ was the predominant antigen recognized, followed by denatured DNA. $35 \%$ of the sera reacted with the dimer-DNA complex. Two sera showed an increase in binding to the (H2A-H2B)-DNA complex compared with binding to $\mathrm{H} 2 \mathrm{~A}-\mathrm{H} 2 \mathrm{~B}$, while six showed a decrease. Three patients showed an increase in binding to the (H3-H4) $)_{2}$-DNA complex compared with $(\mathrm{H} 3-\mathrm{H} 4)_{2}$, while three other sera showed a decrease. Only five sera bound to H1-stripped chromatin and trypsinized H1-stripped chromatin. Thus, the predominant IgG antibody reactivity was directed against $\mathrm{H} 1$ and denatured DNA, but no clear pattern of reactivity was observed.

In contrast to IgG antibodies, there was a distinct pattern of IgM reactivity with the histone and nucleohistone substrates (Fig. 7 B). 12 out of 17 sera contained IgM antibodies reacting with the $\mathrm{H} 2 \mathrm{~A}-\mathrm{H} 2 \mathrm{~B}$ dimer and the $(\mathrm{H} 3-\mathrm{H} 4)_{2}$ tetramer, usually both native and denatured. These sera all showed decreased binding to the corresponding histone-DNA complex, and H1-
Table II. Statistically Significant Differences in Reactivity with Chromatin Constituents at $P<0.002^{*}$

\begin{tabular}{|c|c|}
\hline Antigen & Groups compared ${ }^{t}$ \\
\hline H2A-H2B Dimer & IgG PA-LE vs. IgG QU-LE \\
\hline \multirow[t]{10}{*}{ (H2A-H2B)-DNA } & IgG PA-LE vs. IgG PA-AS \\
\hline & IgG PA-LE vs. IgG HY-LE \\
\hline & IgG PA-LE vs. IgG CZ-AS \\
\hline & IgG PA-LE vs. IgM PA-AS \\
\hline & IgG PA-LE vs. IgM QU-LE \\
\hline & IgG PA-LE vs. IgM HY-LE \\
\hline & IgG PA-LE vs. IgM CZ-AS \\
\hline & IgM PA-LE vs. IgM PA-AS \\
\hline & IgM PA-LE vs. IgM HY-LE \\
\hline & IgM PA-LE vs. IgM CZ-AS \\
\hline \multirow{3}{*}{$(\mathrm{H} 3-\mathrm{H} 4)_{2}$ Tetramer } & IgM CZ-AS vs. IgM PA-LE \\
\hline & IgM HY-LE vs. IgG PA-LE \\
\hline & IgM CZ-AS vs. IgG PA-LE \\
\hline \multirow[t]{8}{*}{ Stripped chromatin } & IgG PA-LE vs. IgG PA-AS \\
\hline & IgG PA-LE vs. IgG HY-LE \\
\hline & IgG PA-LE vs. IgG CZ-AS \\
\hline & IgG PA-LE vs. IgM PA-AS \\
\hline & IgG PA-LE vs. IgM HY-LE \\
\hline & IgG PA-LE vs. IgM CZ-AS \\
\hline & IgM PA-LE vs. IgM HY-LE \\
\hline & IgM PA-LE vs. IgM CZ-AS \\
\hline \multirow[t]{6}{*}{ Denatured DNA } & IgG HY-LE vs. IgG PA-LE \\
\hline & IgM Hy-LE vs. IgG PA-LE \\
\hline & IgM CZ-AS vs. IgG PA-LE \\
\hline & IgM HY-LE vs. IgM PA-LE \\
\hline & IgM CZ-AS vs. IgM PA-LE \\
\hline & IgM HY-LE vs. IgM CZ-LE \\
\hline \multirow[t]{5}{*}{ H1 } & IgG HY-LE vs. IgG PA-LE \\
\hline & IgG CZ-AS vs. IgG PA-LE \\
\hline & IgM HY-AS vs. IgG PA-LE \\
\hline & IgM CZ-AS vs. IgG PA-LE \\
\hline & IgM CZ-AS vs. IgM HY-LE \\
\hline \multirow[t]{3}{*}{ H1-DNA } & IgM QU-LE vs. IgG PA-LE \\
\hline & IgM HY-LE vs. IgG PA-LE \\
\hline & IgM CZ-AS vs. IgG PA-LE \\
\hline
\end{tabular}

* The analysis was performed on the percent of total reactivity data from Table I. An independent-samples two-tailed $t$ test employing a pooled estimate of the variance was used to calculate $P$ values (48). The same or lower $P$-values were obtained using the Wilcoxon twotailed nonparametric test (48) except for anti-(H1-DNA) in which $P$ $<0.05$ for IgM QU-LE vs. IgG PA-LE and $<0.01$ for IgM HY-LE vs. IgG PA-LE. ${ }^{\ddagger}$ The group with the higher mean percent of total reactivity is listed first in the comparison.

stripped chromatin and trypsinized chromatin were the least antigenic histone-containing substrates. 14 of the sera reacted with $\mathrm{H} 1$ and relatively less with H1-DNA. All sera showed some binding to denatured DNA but not to native DNA. This pattern of IgM reactivity is virtually identical to the pattern found in patients treated with chlorpromazine.

Statistical analyses. The ELISA results for IgG and IgM antibodies to all the antigens in the five patient groups are summarized in Table I. The reactivity of a patient group on each antigen is expressed as the average optical density as well as the percent of the total optical density summed over the 
entire panel of antigens. At least three points which may not be obvious from the figures can be abstracted from this data. Firstly, although all of the antigens (except native DNA) displayed capacity to react with at least one of the groups indicating absence of systematic assay bias, each group had no or negligible reactivity on various antigens. Low antigen reactivity contributes to the pattern in all groups except the asymptomatic procainamide-treated group (PA-AS) which had no predominant antigen binding and, therefore, no pattern. Secondly, the standard deviations of the optical densities tend to be much greater than standard deviations of the percent of total reactivity, demonstrating that the absolute amount of antibody activity of the individuals in a patient group varies considerably, but the relative reactivity is remarkably uniform among the individuals within most of the patient groups. For example, the average reactivity of the procainamide-induced lupus group was 3.2 \pm 3.5 OD on native dimer and 9.1 44.6 OD on
dimer-DNA; when expressed as percent of total reactivity the standard deviations were only one-third to one-fourth the mean percent of total reactivity $(5.5 \pm 1.2 \%$ and $28.5 \pm 9.8 \%$, respectively). Finally, the percent total reactivity can be used to compare the IgG with the IgM profile within a patient group, since the absolute signals generated by different class-specific detecting reagents can be ignored. Except for chlorpromazinetreated patients, differences between the IgG and IgM reactivity were found by $t$ test on only one or two of the antigens at a $P$ $<0.05$ level, indicating that the antibody patterns within a group were not generally isotype-dependent.

Expression of the data as percent of total reactivity also allowed comparison between patient groups regardless of the immunoglobulin class as shown in Table II. For simplicity, the displayed data focus on the two dominant patterns of reactivity as typified by procainamide-induced lupus and Tydralazine-induced lupus. The IgG and IgM reactivities from only these two

Table III. Effect of Chromatin Absorption on Drug-induced Antibodies

\begin{tabular}{|c|c|c|c|c|c|c|c|}
\hline \multirow[b]{2}{*}{ Serum } & \multirow[b]{2}{*}{ Dilution $^{-1}$} & \multirow[b]{2}{*}{ Absorbent } & \multicolumn{5}{|c|}{ ELISA reactivity after absorption (mean $\mathrm{OD} \pm \mathrm{SD}$ )* } \\
\hline & & & STR CHR & DIM-DNA & NAT TET & H1 & Tetanus \\
\hline \multirow[t]{2}{*}{ PA-LE1 } & 60,000 & Collagen & $0.9 \pm 0.1$ & $0.5 \pm 0.0$ & ND & ND & $0.0 \pm 0.0$ \\
\hline & & Chromatin & $0.0 \pm 0.0$ & $0.0 \pm 0.0$ & ND & ND & $0.0 \pm 0.0$ \\
\hline \multirow[t]{2}{*}{ PA-LE2 } & 500 & Collagen & $2.9 \pm 0.7$ & $1.5 \pm 0.1$ & ND & ND & $0.0 \pm 0.0$ \\
\hline & & Chromatin & $0.6 \pm 0.1$ & $0.5 \pm 0.1$ & ND & ND & $0.1 \pm 0.0$ \\
\hline \multirow[t]{2}{*}{ PA-LE3 } & 600 & Collagen & $1.4 \pm 0.1$ & $0.7 \pm 0.0$ & ND & ND & $1.3 \pm 0.1$ \\
\hline & & Chromatin & $0.0 \pm 0.0$ & $0.0 \pm 0.0$ & ND & ND & $1.7 \pm 0.3$ \\
\hline \multirow[t]{2}{*}{ PA-LE4 } & 2,100 & Collagen & $2.0 \pm 0.3$ & $1.5 \pm 0.4$ & ND & ND & $2.1 \pm 0.1$ \\
\hline & & Chromatin & $0.1 \pm 0.0$ & $0.1 \pm 0.0$ & ND & ND & $2.0 \pm 0.0$ \\
\hline \multirow[t]{2}{*}{ QU-LE1 } & 600 & Collagen & $7.4 \pm 1.2$ & $3.4 \pm 0.6$ & ND & ND & $1.0 \pm 0.1$ \\
\hline & & Chromatin & $1.2 \pm 0.1$ & $0.8 \pm 0.1$ & ND & ND & $0.9 \pm 0.3$ \\
\hline \multirow[t]{2}{*}{ QU-LE2 } & 600 & Collagen & $1.1 \pm 0.1$ & $0.6 \pm 0.0$ & ND & ND & $0.0 \pm 0.0$ \\
\hline & & Chromatin & $0.1 \pm 0.0$ & $0.1 \pm 0.0$ & ND & ND & $0.0 \pm 0.0$ \\
\hline \multirow[t]{2}{*}{ QU-LE3 } & 60 & Collagen & $1.2 \pm 0.1$ & $0.3 \pm 0.1$ & ND & ND & $1.7 \pm 0.4$ \\
\hline & & Chromatin & $0.0 \pm 0.0$ & $0.0 \pm 0.0$ & ND & ND & $1.5 \pm 0.4$ \\
\hline \multirow[t]{2}{*}{ QU-LE4 } & 250 & Collagen & $0.0 \pm 0.0$ & $1.4 \pm 0.1$ & ND & ND & $1.7 \pm 0.1$ \\
\hline & & Chromatin & $0.0 \pm 0.0$ & $1.9 \pm 0.2$ & ND & ND & $2.2 \pm 0.2$ \\
\hline \multirow[t]{2}{*}{$\mathrm{CZl}$} & 400 & Collagen & ND & ND & $3.0 \pm 0.1$ & $2.1 \pm 0.1$ & $1.0 \pm 0.1$ \\
\hline & & Chromatin & ND & ND & $3.0 \pm 0.1$ & $2.0 \pm 0.1$ & $0.9 \pm 0.2$ \\
\hline \multirow[t]{2}{*}{$\mathrm{CZ2}$} & 600 & Collagen & ND & ND & $2.4 \pm 0.0$ & $3.0 \pm 0.0$ & $0.0 \pm 0.0$ \\
\hline & & Chromatin & ND & ND & $2.4 \pm 0.1$ & $2.8 \pm 0.2$ & $0.0 \pm 0.0$ \\
\hline \multirow[t]{2}{*}{$\mathrm{CZ3}$} & 600 & Collagen & ND & ND & $3.2 \pm 0.1$ & $3.3 \pm 0.1$ & $0.1 \pm 0.0$ \\
\hline & & Chromatin & ND & ND & $3.0 \pm 0.1$ & $3.2 \pm 0.1$ & $0.1 \pm 0.0$ \\
\hline \multirow[t]{2}{*}{ CZ4 } & 600 & Collagen & ND & ND & $1.3 \pm 0.1$ & $2.6 \pm 0.0$ & $0.6 \pm 0.1$ \\
\hline & & Chromatin & ND & ND & $1.2 \pm 0.1$ & $2.3 \pm 0.1$ & $0.4 \pm 0.1$ \\
\hline \multirow[t]{2}{*}{ HY-LE1 } & 400 & Collagen & ND & ND & $0.7 \pm 0.1$ & $2.5 \pm 0.0$ & $0.3 \pm 0.1$ \\
\hline & & Chromatin & ND & ND & $0.4 \pm 0.1$ & $1.9 \pm 0.1$ & $0.3 \pm 0.1$ \\
\hline \multirow[t]{2}{*}{ HY-LE2 } & 400 & Collagen & ND & ND & $2.4 \pm 0.1$ & $1.8 \pm 0.2$ & $0.0 \pm 0.0$ \\
\hline & & Chromatin & ND & ND & $2.2 \pm 0.0$ & $1.6 \pm 0.1$ & $0.0 \pm 0.0$ \\
\hline \multirow[t]{2}{*}{ HY-LE3 } & 300 & Collagen & ND & ND & $1.1 \pm 0.1$ & $2.3 \pm 0.1$ & $0.2 \pm 0.0$ \\
\hline & & Chromatin & ND & ND & $0.6 \pm 0.0$ & $2.0 \pm 0.2$ & $0.1 \pm 0.0$ \\
\hline \multirow[t]{2}{*}{ HY-LE4 } & 150 & Collagen & ND & ND & $2.2 \pm 0.1$ & $1.2 \pm 0.1$ & $0.0 \pm 0.0$ \\
\hline & & Chromatin & ND & ND & $2.1 \pm 0.1$ & $1.1 \pm 0.0$ & $0.0 \pm 0.0$ \\
\hline
\end{tabular}

* Sera were diluted to produce $<3$ OD on dimer-DNA or native tetramer, treated with $22 \mu \mathrm{g} / \mathrm{ml}$ chromatin or collagen, and tested for residual antibody to the appropriate substrate. See Fig. 3 for the substrate and Table I for the serum abbreviations. The detecting reagent for stripped chromatin, dimer-DNA, and tetanus was anti-IgG, and for native tetramer and $\mathrm{H} 1$ was anti-IgM. 
groups were compared with the IgG and IgM reactivities of all the other groups for a total of nine comparisons for each antigen. Only the statistical analyses of the average percent of total data are shown, although similar results based on average optical densities were obtained. In addition, comparisons with the denatured histones and native DNA are not shown because antibody activities to these antigens were generally low, and trypsinized chromatin is not shown 'since it was essentially the same as H1-stripped chromatin. Statistically significant differences only at $P<0.002$ are displayed in Table II to comply with an optional correction for the nine comparisons performed with each antigen. Anti-([H2A-H2B]-DNA) was significantly elevated in procainamide-induced lupus for both IgG and IgM antibodies when compared to all the other groups except IgG quinidine-induced lupus. Similar differences were observed with H1-stripped chromatin, presumably due to the presence of (H2A-H2B)-DNA complexes in this preparation. The other pattern, dominated by the DNA-free $\mathrm{H} 3-\mathrm{H} 4$ tetramer, $\mathrm{H} 1$ and denatured DNA and as exemplified by IgM antibodies in hydralazine-induced lupus and chlorpromazine-treated patients, was fully supported by the statistical analyses at a $P$ value $<0.002$. No differences between hydralazine-induced lupus and chlorpromazine-induced autoimmunity were observed on most of the antigens, verifying the similarity in the patterns in these two patient groups. The only difference between these two groups was higher IgM antidenatured DNA in hydralazine-induced lupus and higher IgM anti-H1 in chlorpromazine-induced autoimmunity $(P<0.002)$ when expressed as percent of total antibody (but not as average optical density). When all patients with quinidine-induced lupus were considered, there was no significant difference in the binding of dimer-DNA or stripped chromatin when compared to hydralazine-induced lupus, due to the high standard deviation in the former group. However, as a group, the seven quinidine-induced lupus patients with anti-(dimer-DNA) reactivity were significantly different from the hydralazine-induced lupus patients $(P<0.001)$ for binding to this antigen and trypsinized chromatin. Because some of the data did not follow a normal distribution, they were also analyzed by the Wilcoxon twotailed rank sum test, producing the same or lower $P$ value statistics except for two comparisons (Table II). In summary, the apparent patterns of reactivity revealed by visual inspection of the figures are supported by objective statistical analyses, suggesting that these data have biologic significance.

Absorption studies. The ELISA studies indicate that antibodies in patients with procainamide-induced lupus and a subset of patients with quinidine-induced lupus bind primarily to native histone-DNA complexes, while patients treated with hydralazine and chlorpromazine recognize histone epitopes not exposed in chromatin. However, macromolecular substrates may be partially denatured when bound to plastic substrates in ELISA formats, allowing detection of nonnative epitopes (35, 36). To examine this question, we determined the capacity of whole chromatin, the most native form of nucleohistone, to bind antibodies in liquid phase. Chromatin-absorbed sera were tested for residual antibody using the appropriate ELISA substrate and compared to the same sera treated with collagen, an insoluble hydrophilic protein mixture which serves as an inert control immunosorbent. Possible nonspecific absorption by chromatin was also monitored by simultaneous measurement of antitetanus antibodies.

For four unselected sera from patients with procainamide- induced lupus, chromatin absorbed an average of $92 \%$ of the anti-H1-stripped chromatin binding and $89 \%$ of the reactivity to dimer-DNA, while antitetanus remained essentially unchanged (Table III). Calculations from chromatin titration studies indicated that preabsorption with $\sim 100 \mathrm{ng}$ chromatin had the capacity to remove $50 \%$ of the antichromatin binding in a single ELISA well (data not shown), suggesting that these liquid and solid phase macromolecular complexes are antigenically similar. (There is $225 \mathrm{ng} \mathrm{H1}$-stripped chromatin on the solid phase [24]).

Three of four sera from patients with quinidine-induced lupus displayed similarly efficient antibody absorption by chromatin without significantly altering antitetanus levels. Interestingly, antibody in QU-LE4 that bound dimer-DNA but not stripped chromatin in ELISA was unaffected by chromatin absorption, indicating that the epitope in dimer-DNA targeted by this serum is not expressed on either solid or liquid phase chromatin.

In contrast to the results with procainamide- and quinidine-induced lupus sera, an average of only $25 \%$ of the (H3$\mathrm{H} 4)_{2}$ tetramer reactivity and $14 \%$ of the $\mathrm{H} 1$ reactivity was removed by chromatin absorption of the hydralazine-induced lupus group, and $3 \%$ and $7 \%$, respectively, from the sera of chlorpromazine-treated patients. The inability of chromatin to absorb out these antibodies was not related to their IgM isotype because an average of $83 \%$ of the IgM antistripped chromatin reactivity was removed by chromatin absorption of sera from patients with procainamide-induced lupus (data not shown). These solution absorption studies are, therefore, consistent with the previous results, demonstrating that sera from chlorpromazine- and hydralazine-treated patients displayed negligible binding to H1-stripped chromatin in ELISA and indicate that the targeted epitopes on $\mathrm{H} 1$ and tetramer are hidden when these histones are presented as chromatin.

\section{Discussion}

In this study all known forms of native histone-histone and histone-DNA complexes were used as antigens in ELISA to characterize autoantibodies induced by various drugs. Two distinct patterns of reactivity related to chromatin structure were discovered. One pattern, characteristic of all patients with procainamide- and a subset of quinidine-induced lupus, was dominated by the highly antigenic (H2A-H2B)-DNA complex. Sera from these patients uniformly showed less or, in the case of quinidine-induced lupus, no reactivity with $\mathrm{H} 2 \mathrm{~A}-\mathrm{H} 2 \mathrm{~B}$ free of DNA. Since these sera did not bind DNA by itself, the epitope may require the quaternary interaction of both histone and DNA or may be stabilized in the protein by DNA. Only regions of the dimer exposed in chromatin appear to be reactive since most of these sera displayed similarly high levels of binding to H1-stripped chromatin and absorption with chromatin removed reactivity to dimer-DNA. Strikingly, antibodies to the $(\mathrm{H} 3-\mathrm{H} 4)_{2}$ tetramer or the tetramer-DNA complex were absent or relatively low in these patients, even though these structures make up a major portion of chromatin.

A remarkably different pattern of antibody reactivity was displayed by IgM antibodies induced by chlorpromazine or hydralazine. In these cases, the predominant reactivity was with the DNA-free histones $\mathrm{H} 2 \mathrm{~A}-\mathrm{H} 2 \mathrm{~B}, \mathrm{H} 3-\mathrm{H} 4$, and $\mathrm{H} 1$. The corresponding histone-DNA complexes had uniformly lower reactivity and $\mathrm{H} 1$-stripped chromatin usually had even lower 
antigenicity, suggesting that the target epitopes are the protein regions covered by DNA and buried by protein-protein interactions in chromatin (see Fig. 1). This conclusion is supported by results from liquid phase absorption, demonstrating that chromatin did not remove anti-H1 or antitetramer antibodies in these sera.

One reason for evaluating all known forms of histone-histone complexes and subnucleosome structures was to determine if there was a correlation between antibody reactivity and symptoms of drug-induced lupus. Previous work had shown that reactivity with the DNA-free H2A-H2B dimer can discriminate between most symptomatic and asymptomatic procainamide-treated patients $(8,10)$, and this work confirms those findings. In this study, three symptomatic patients did not have antibodies reacting with the $\mathrm{H} 2 \mathrm{~A}-\mathrm{H} 2 \mathrm{~B}$ dimer, and two others reacted at a very low level, showing false negativity in this assay. Using a cutoff level of 2 SD above the average of 20 normals, six of the asymptomatic patients reacted with the DNAfree dimer, and therefore would be considered falsely positive by this criterion. However, binding to the (H2A-H2B)-DNA complex gave better discrimination between symptomatic and asymptomatic patients. None of the 21 procainamide-treated patients having lupus-like symptoms had a reactivity on $(\mathrm{H} 2 \mathrm{~A}$ H2B)-DNA $<1$ OD. In contrast, only 2 of the asymptomatic procainamide-treated patients produced an OD $>1$. From Table $I$ it can be seen that the asymptomatic patients had an average OD of 0.3 on both the dimer and dimer-DNA. For symptomatic patients, the average OD on the dimer was 3.2, while it was 9.1 on dimer-DNA, a significant difference at $P$ $<0.001$. Thus the presence of IgG antibodies reactive with the (H2A-H2B)-DNA complex is a better diagnostic marker for procainamide-induced lupus than antibodies reactive with DNA-free H2A-H2B.

Previous characterizations of drug-induced antihistone antibodies primarily measured reactivity with individual histones or histone fragments rather than chromatin substructures, so direct comparison with the current results is difficult. Sera from patients with hydralazine-induced lupus were reported to predominantly react with $\mathrm{H} 3$ and $\mathrm{H} 4$ (9), although other studies failed to detect a distinct pattern of IgG reactivity with individual histones using solid-phase assays (37) or Western blot (12). Chlorpromazine-induced antihistone antibodies were reported to display relatively uniform binding with the substrates tested (5).

One difference between the present results and previous work concerns the antigenicity of the trypsin-resistant regions of histones. With the Western blot technique, sera from most patients with procainamide-induced lupus did not bind the trypsin-resistant histone cores $(11,12)$, while with ELISA we found that these regions were strongly antigenic in the form of trypsinized chromatin. The most likely explanation for this discrepancy is that the antibodies we detected recognized a quaternary structure in native and trypsinized chromatin which is lost during preparation or immobilization of individual histones. Portanova et al. (9) demonstrated that sera from patients with procainamide-induced lupus bound the trypsin resistant cores of $\mathrm{H} 2 \mathrm{~A}$ and $\mathrm{H} 2 \mathrm{~B}$. This antibody activity may be directed to the quaternary structure epitope on the H2A-H2B complex that was demonstrated to reassemble during transfer of H2A and H2B to nitrocellulose in the absence of SDS (9).

The uniform patterns of reactivity of drug-induced autoantibodies raise a number of questions regarding their origin and significance. One issue concerns the different isotypes and specificities of antibodies in symptomatic compared to asymptomatic drug-treated patients. The simplest explanation for a symptom-associated antibody is that only these antihistone antibodies are somehow pathogenic. In this way individuals who happen to develop IgG anti-(dimer-DNA) antibodies develop symptoms of lupus. However, it is important to realize that after discontinuation of therapy, lupus-like symptoms usually subside much sooner than do autoantibodies, so that it is common for a patient to be free of symptoms but still retain considerable anti-(dimer-DNA) activity (data not shown). This feature suggests that if these antibodies are pathogenic, another factor related to continuous drug exposure may be required for expression of pathogenicity, such as drug-dependent generation of an unusual form of the target antigen in order for pathogenic immune complexes to be produced in vivo. Alternatively, elicitation of IgG anti-(dimer-DNA) could be merely linked in time with an unknown pathogenic process and this antibody may not be directly involved in that process itself.

Another interesting observation is the strong tendency for the isotype of drug-induced antibodies in asymptomatic patients to be predominantly IgM. IgM-restricted immune responses are generally interpreted to suggest $\mathrm{T}$ cell independent processes such as direct B cell activation by polyclonal stimulators (38). Although the antibodies in procainamide-treated asymptomatic patients reacted with a wide range of histone antigens and therefore appear nonspecific, procainamide-induced antibodies are restricted to histone- or denatured DNAcontaining materials, and other autoantibody specificities or antibodies to exogenous agents are not detected (39). Furthermore, a unique pattern of IgM reactivity on the set of subnucleosome structures was observed in chlorpromazine-treated asymptomatic patients. A predominant and sustained IgM response occurs in animals immunized with particulate forms of protein antigens such as bovine albumin (40), human thyroglobulin (41), and to the nuclear antigens Sm and histones (36), and the antihistone response is thymus-dependent (36). Drugelicited IgM antihistone antibodies in asymptomatic patients resemble the pseudoautoantibodies elicited in normal mice immunized with histones adsorbed to latex beads (36) in that binding to DNA-free histones predominates over binding to more native forms of histone such as histone-DNA complexes, chromatin, and nuclei. It might be suggested, therefore, that asymptomatic patients retain substantial autoimmune tolerance to chromatin at the B cell level whereas B cell tolerance is lost only in symptomatic patients displaying $\mathrm{IgG}$ antibodies to histone-DNA complexes.

The most provocative question raised by these studies concerns the mechanism underlying drug induction of autoantibodies and the basis for the association of some drugs with a predominant reactivity with only certain chromatin components. Allergic-like hypersensitivity reactions to drugs such as penicillin (42) are commonly used as a paradigm for the autoimmune responses in drug-induced lupus. In this way drugs might be thought to bind to histone-containing self material, altering it to produce nonnative or even foreign epitopes, breaking B cell tolerance to autoantigens. $T$ cell help could derive from a drug-specific response such as the experimental lymphoproliferation induced in mice by injection of penicillamine, streptozotocin, and gold salts (43), or from nonspecific, direct lymphocyte activation observed in vitro by drugs such as procainamide (44) or its metabolite, procainamide-hydroxyl- 
amine (45). However, autoantibody binding does not require the presence of drug since the nucleohistones used as antigens were derived from calf thymus, and drug carry-over from patients' sera would be insignificant after dilution or a few days after withdrawal of therapy. Furthermore, drug elicitation of autoantibodies does not follow the kinetics and drug dose dependency of a classical drug allergy, and antidrug antibodies have been only rarely reported. More subtle mechanisms may be involved such as drug perturbation of lymphocyte homeostatic mechanisms mimicking the processes occurring during $T$ cell activation by MHC class II incompatible structures in experimental graft-vs.-host reaction (46). However, these concepts fail to provide a credible explanation for the restricted specificity of the drug-induced antibodies to histone-containing structures. One way a specific response might develop is if drug metabolites perturbed chromatin or histone catabolism, resulting in an immunogenic form of self material with concomitant loss of B cell tolerance to parts of the self immunogen.

The two patterns of antibody binding to nucleosome components suggest that there may be two pathways for autoantibody induction by drugs. Although we can only speculate on the nature of these pathways, it is clear that both patterns are related to chromatin structure and are essentially reciprocally related to each other. With one pattern, DNA enhanced antigenicity and the epitopes were exposed in chromatin, while in the other pattern epitopes were partially blocked by DNA and not exposed in chromatin. Thus, the intermolecular interactions underlying chromatin structure strongly affect its antigenicity, suggesting that production of these antibodies is linked to a process involving autoimmunization with histones or chromatin.

\section{Acknowledgments}

We thank the Divisions of Rheumatology and Cardiovascular Diseases of Scripps Clinic for patient material and clinical information, especially Drs. Mark C. Totoritis, Frank Kozin, and Edward M. McNally. Sera from chlorpromazine-treated patients were obtained from Dr. Mohammad H. Zarrabi, VA Medical Center, Northport, NY, and Dr. Lee D. Kaufman, Health Science Center, State University of New York, Stony Brook, NY. The excellent technical assistance of Ms. Judy Zubar is appreciated.

This work was supported in part by grants AR-34358 from the National Institutes of Health, and RR00833 from the U.S. Public Health Service. Dr. Burlingame is a Postdoctoral Fellow of the Arthritis Foundation. This is publication number 5958MEM from the Research Institute of Scripps Clinic, La Jolla.

\section{References}

1. Hess, E. 1988. Drug-related lupus. N. Engl. J. Med. 318:1460-1462.

2. Harmon, C. H., and J. P. Portanova. 1982. Drug-induced lupus: clinical and serological studies. Clin. Rheum. Dis. 8:121-135.

3. Woosley, R. L., D. E. Drayer, M. M. Reidenberg, A. S. Nies, K. Carr, and J. A. Oates. 1978. Effect of acetylator phenotype on the rate at which procainamide induces antinuclear antibodies and the lupus syndrome. $N$. Engl. J. Med. 298:1157-1159.

4. Litwin, A., L. E. Adams, H. Zimmer, B. Foad, J. H. M. Loggie, and E. V. Hess. 1981. Prospective study of immunologic effects of hydralazine in hypertensive patients. Clin. Pharmacol. \& Ther. 29:447-456.

5. Canoso, R. T., and R. M. de Oliveira. 1986. Characterization and antigenic specificity of chlorpromazine-induced antinuclear antibodies. J. Lab. Clin. Med. 108:213-216.

6. Cohen, M. G., S. Kevat, M. V. Prowse, and M. J. Ahern. 1988. Two distinct quinidine induced rheumatic syndromes. Ann. Intern. Med. 108:369-371.
7. Tan, E. M., E. K. L. Chan, K. F. Sullivan, and R. L. Rubin. 1988. Antinuclear antibodies (ANAs): diagnostically specific immune markers and clues toward the understanding of systemic autoimmunity. Clin. Immunol. Immunopathol. 47:121-141.

8. Rubin, R. L., E. M. McNally, S. R. Nusinow, C. A. Robinson, and E. M Tan. 1985. IgG antibodies to the histone complex H2A-H2B characterize procainamide-induced lupus. Clin. Immunol. Immunopathol. 36:49-59.

9. Portanova, J. P., R. E. Arndt, E. M. Tan, and B. L. Kotzin. 1987. Anti-histone antibodies in idiopathic and drug-induced lupus recognize distinct intrahistone regions. J. Immunol. 138:446-451.

10. Totoritis, M. C., E. M. Tan, E. M. McNally, and R. L. Rubin. 1988 Association of antibody to histone complex $\mathrm{H} 2 \mathrm{~A}-\mathrm{H} 2 \mathrm{~B}$ with symptomatic procainamide-induced lupus. N. Engl. J. Med. 318:1431-1436.

11. Gohill, J., P. D. Cary, M. Couppez, and M. J. Fritzler. 1985. Antibodies from patients with drug-induced and idiopathic lupus erythematosus react with epitopes restricted to the amino and carboxyl termini of histone. J. Immunol. 135:3116-3121.

12. Craft, J. E., J. A. Radding, M. W. Harding, R. M. Bernstein, and J. A. Hardin. 1987. Autoantigenic histone epitopes: a comparison between procainamide- and hydralazine-induced lupus. Arthritis Rheum. 30:689-694.

13. Burlingame, R. W., W. E. Love, T. H. Eickbush, and E. N. Moudrianakis. 1986. The structure of the histone octamer and its dynamics in chromatin function. In Biomolecular Stereodynamics III. Proceedings of the Fourth Conversation in the Discipline Biomolecular Stereodynamics. R. H. Sarma and M. H. Sarma, editors. Adenine Press, Guilderland, NY. 11-33.

14. Lutter, L. C. 1978. Kinetic analysis of deoxyribonuclease I cleavages in the nucleosome core: evidence for a DNA superhelix. J. Mol. Biol. 124:391-420.

15. Nelson, D. A., A. J. Mencke, S. A. Chambers, D. K. Oosterhof, and R. L. Rill. 1982. Subnucleosomes and their relationships to the arrangement of histone binding sites along nucleosome deoxyribonucleic acid. Biochemistry. 21:43504362.

16. Eickbush, T. H., and E. N. Moudrianakis. 1978. The histone core complex: an octamer assembled by two sets of protein-protein interactions. Biochemistry. 17:4955-4964.

17. Richmond, T. J., J. T. Finch, B. Rushton, D. Rhodes, and A. Klug. 1984. Structure of the nucleosome core particle at $7 \mathrm{~A}$ resolution. Nature (Lond.). 311:532-537.

18. Burlingame, R. W., W. E. Love, B.-C. Wang, R. Hamlin, N.-H. Xuong, and E. N. Moudrianakis. 1985. Crystallographic structure of the octameric histone core of the nucleosome at a resolution of 3.3 A. Science (Wash. DC). 228:546-553.

19. Benedict, R. C., E. N. Moudrianakis, and G. K. Ackers. 1984. Interactions of the nucleosomal core histones: a calorimetric study of octamer assembly. Biochemistry. 23:1214-1218.

20. Read, C. M., J. P. Baldwin, and C. Crane-Robinson. 1985. Structure of sub-nucleosomal particles. Tetrameric $\left(\mathrm{H} 3 / \mathrm{H}_{4}\right)_{2} 146$ base pair DNA and hexameric $(\mathrm{H} 3 / \mathrm{H} 4)_{2}(\mathrm{H} 2 \mathrm{~A} / \mathrm{H} 2 \mathrm{~B})_{1} 146$ base pair DNA complexes. Biochemistry. 24:4435-4450.

21. Oohara, I., and A. Wada. 1987. Spectroscopic studies on histone-DNA interactions I. The interaction of histone (H2A, H2B) dimer with DNA: DNA sequence dependence. J. Mol. Biol. 196:389-397.

22. Mencke, A. J., and R. L. Rill. 1982. Circular dichroism and thermal denaturation studies of subnucleosomes and their relationships to nucleosome structure. Biochemistry. 21:4362-4370.

23. Weintraub, H., and F. Van Lente. 1974. Dissection of chromosome structure with trypsin and nucleases. Proc. Natl. Acad. Sci. USA. 71:4249-4253.

24. Burlingame, R. W., and R. L. Rubin. 1990. Subnucleosome structures as substrates in enzyme-linked immunosorbent assays. J. Immunol. Methods. 134:187-199.

25. Oohara, I., and A. Wada. 1987. Spectroscopic studies on histone-DNA interactions II. Three transitions in nucleosomes resolved by salt-titration. $\mathrm{J}$. Mol. Biol. 196:399-411.

26. Rubin, R. L. 1986. Enzyme-linked immunosorbent assay for anti-DNA and anti-histone antibodies. In Manual of Clinical Laboratory Immunology. N. R. Rose, H. Friedman, and J. L. Fahey, editors. ASM, Washington, DC. 744-749.

27. Maniatis, T., E. F. Fritsch, and J. Sambrook. 1982. Molecular Cloning: A Laboratory Manual. Cold Spring Harbor Laboratory, Cold Spring Harbor, NY.

28. Rubin, R. L., F-L. Tang, A. H. Lucas, H. L. Spiegelberg, and E. M. Tan. 1986. IgG subclasses of anti-tetanus toxoid antibodies in adult and newborn normal subjects and in patients with systemic lupus erythematosus, Sjogren's syndrome, and drug-induced autoimmunity. J. Immunol. 137:2522-2527.

29. Smith, P. K., R. I. Krohn, G. T. Hermanson, A. K. Mallia, F. H. Gartner, M. D. Provenzano, E. K. Fujimoto, N. M. Goeke, B. J. Olson, and D. C. Klenk. 1985. Measurement of protein using bicinchoninic acid. Anal. Biochem. 150:7685 .

30. Kotzin, B. L., J. A. Lafferty, J. P. Portanova, R. L. Rubin, and E. M. Tan. 1984. Monoclonal anti-histone autoantibodies derived from murine models of lupus. J. Immunol. 133:2554-2559. 
31. Pollard, K. M., E. K. L. Chan, R. L. Rubin, and E. M. Tan. 1987. Monoclonal autoantibodies to nuclear antigens from murine graft-versus-host disease. Clin. Immunol. Immunopathol. 44:31-40.

32. Zarrabi, M. H., L. Kaufman, B. Gruber, R. Rubin, M. Reichlin, and J. Harley. 1988. Further characterization of the serologic immune response to chlorpromazine (CPZ). Blood. 72:1007.

33. Laemmli, U. K. 1970. Cleavage of structural proteins during the assembly of the head of bacteriophage T4. Nature (Lond.). 227:680-685.

34. Bohm, L., and C. Crane-Robinson. 1984. Proteases as structural probes for chromatin: the domain structure of histones. Biosci. Rep. 4:365-386.

35. Jemmerson, R. 1987. Polypeptide fragments of horse cytochrome c activate a small subset of secondary $B$ lymphocytes primed against the native protein. J. Immunol. 139:1939-1945.

36. Rubin, R. L., F-L. Tang, G. Tsay, and K. M. Pollard. 1990. Pseudoautoimmunity in normal mice: anti-histone antibodies elicited by immunization versus induction during graft-versus-host reaction. Clin. Immunol. Immunopathol. 54:320-332.

37. Hobbs, R. N., A-L. Clayton, and R. M. Bernstein. 1987. Antibodies to the five histones and poly(adenosine diphosphate-ribose) in drug induced lupus: implications for pathogenesis. Ann. Rheum. Dis. 46:408-416.

38. Teale, J. M., and N. R. Klinman. 1984. Control of the production of different classes of antibody. In Fundamental Immunology. W. E. Paul, editor Raven Press, New York. 519-535.

39. Rubin, R. L., G. Reimer, E. M. McNally, S. R. Nusinow, R. P. Searles, and E. M. Tan. 1986. Procainamide elicits a selective autoantibody immune response. Clin. Exp. Immunol. 63:58-67.
40. Draper, L. R., and A. A. Hirata. 1968. Antibody responses in rabbits to soluble and particulate forms of bovine serum albumin. Immunology. 15:23-30.

41. Torrigiani, G., and I. M. Roitt. 1965 . The enhancement of 19 S antibody production by particulate antigen. J. Exp. Med. 181-193.

42. Parker, C. W. 1981. Hapten immunology and allergic reactions in humans. Arthritis Rheum. 24:1024-1036.

43. Gleichmann, E., H.-W. Vohr, C. Stringer, J. Nuyens, and H. Gleichmann. 1989. Testing the sensitization of $T$ cells to chemicals. From murine graft-versushost $(\mathrm{GVH})$ reactions to chemical-induced GVH-like immunological diseases. In Autoimmunity and Toxicology. M. E. Kammuller, N. Bloksma, and W. Seinen, editors. Elsevier Science Publishers B.V., Amsterdam. 363-390.

44. Richardson, B., E. Cornacchia, J. Golbus, J. Maybaum, J. Strahler, and S. Hanash. 1988. $\mathrm{N}$-acetylprocainamide is a less potent inducer of $\mathrm{T}$ cell autoreactivity than procainamide. Arthritis Rheum. 31:995-999.

45. Adams, L. E., C. E. Sanders, Jr., R. A. Budinsky, R. Donovan-Brand, S. M. Roberts, and E. V. Hess. 1989. Immunomodulatory effects of procain amide metabolites: their implications in drug-related lupus. J. Lab. Clin. Med. 113:482-492.

46. Gleichmann, E., E. H. van Elven, and J. P. W. Van der Veen. 1982 . A systemic lupus erythematosus (SLE)-like disease in mice induced by abnormal T-B cell collaboration. Preferential formation of autoantibodies characteristic of SLE. Eur. J. Immunol. 12:152-159.

47. Eickbush, T. H., D. K. Watson, and E. N. Moudrianakis. 1976. A chromatin-bound proteolytic activity with unique specificity for histone H2A. Cell. 9:785-792.

48. Colton, T. 1974. Statistics in Medicine. Little, Brown and Co., Boston. 